\title{
Mille poupées!
}

C.-F. Robert

Correspondance:

Dr Claude-François Robert CP 1111

CH-1211 Genève 26
- Mille poupées! J'ai au moins mille poupées ... C'était sans doute vrai. Des armoires pleines, des rangées entières de bibliothèques, peuplées de petits êtres assis, immobiles, de toutes tailles du foetus au gros bébé, vêtus de langes, de robes, d'atours nuptiaux. Quelques bougies aussi, aux senteurs parfumées, qu'elle avait réparties sur un guéridon.

Elle restait couchée à plat sur le lit, un modèle d'avant-guerre en bois, et se tenait le ventre à cause des douleurs, ondulant lentement pour chasser les crampes. J'attendais que l'antalgie agisse, en silence, observé de deux mille yeux.

«Rue des Jonquilles, une maison ancienne, derrière la fontaine», m'avait-elle indiqué au téléphone. J'imagine qu'elle y a toujours vécu. Sa clinique de poupée était connue de toute les fillettes, à l'époque. Plus maintenant, on ne répare pas les «barbies», on les jette depuis Marylin.

- Vous savez, je n'ai pas eu d'enfants, alors.

Une poupée, j'en avais tenu une dans mes bras une heure avant. Elle pesait huit kilos et braillait comme une trompette. Ses parents désemparés ne savaient plus y faire.

- Elle refuse le biberon, implorait la mère.

- Je la berce depuis trois heures, soupirait le père.

Pas de fièvre, pas de douleurs, tympans nets, guilis-guilis, on sourit au docteur et voilà les parents piteux. Empathique, rassurant, je prodigue quelques conseils. Je m'inspire plus de mon expérience paternelle que des connaissances facultaires. Pas de grand-mère à l'horizon pour ce jeune couple, juste le désarroi qui conduit à appeler le médecin de garde en pleine nuit, la peur de faire faux.

- Donc, vous n'avez pas eu d'enfants ...

Les douleurs se sont calmées; les souvenirs reprennent le dessus.

- J'avais fait une fausse couche, avec hémorragie. C'était la guerre, il n'y avait pas tous ces traitements. Dire que maintenant, une femme de soixante ans peut porter un bébé ...

Son regard s'est élevé vers les rangées de poupées.

- J'ai eu si mal ...

Lors de la fausse couche ou il y a une heure? Le temps s'est contracté. Je me souviens de son allure quand je suis entré dans l'appartement. Elle n'avait pas verrouillé la porte. J'ai parcouru le corridor sombre, en évitant de bousculer les bibelots, attiré par la lueur des bougies dans la pièce. Avec l'expérience, on saisit d'un coup la situation, une image et l'odeur qui va avec, masquée difficilement par le parfum du suif consumé. Sans chercher, le diagnostic s'impose. Bien sûr, il faudra vérifier, investiguer, mais c'est souvent juste, hélas. La lampe de chevet l'éclairait, lui donnant un teint cireux, comme ces visages de céramique au-dessus. Elle se tenait le ventre à pleine main. Elle avait beaucoup maigri depuis le dernier contrôle au cabinet. Pancréas? Cancer de l'estomac?

Maintenant, elle souriait, apaisée. Une mèche projeta une longue flamme en grésillant.

- Mille bébés! Ce serait trop pour une seule femme.

Et dans ses yeux, au soir de sa vie, se reflétaient les regards ternes de ses mille poupées, comme autant d'enfants jamais grandis. 